\title{
SEGURANÇA ALIMENTAR E NUTRICIONAL NO CONTEXTO HISTÓRICO E CULTURAL DE PORTO VERA CRUZ/RS
}

\begin{abstract}
Sandra Cristina Franchikoski ${ }^{1}$; Susana Cesco ${ }^{2}$.
1 - Possui Graduação em Nutrição (2001), Especialização em Nutrição Clínica (2004) pela Universidade Regional do Noroeste do Estado do Rio Grande do Sul (UNIJUI) e Mestrado em Políticas Públicas pela Universidade Federal do Pampa (Unipampa) - Campus São Borja/RS. Atualmente é Assistente em Administração do Instituto Federal Farroupilha. Tem experiência na área de Nutrição Clínica, Alimentação Escolar, Alimentação Hospitalar, Unidade de Alimentação e Nutrição, Saúde Pública e Gestão de Políticas Públicas. Também possui experiência profissional na área de Ensino, Licitações e Gestão Documental.

2 - Doutora em História Social pela Universidade Federal do Rio de Janeiro (2009), mestre em História Cultural pela Universidade Federal de Santa Catarina (2005), bacharel e licenciada em História pela Universidade Federal de Santa Catarina (2003). Professora Recém-doutora (bolsista PRODOC/CAPES) no Programa de Pós-Graduação de Ciências Sociais em Desenvolvimento, Agricultura e Sociedade CPDA/UFRRJ no período 2010 à 2013. Professora no Programa de Pós-Graduação em Políticas Públicas da Universidade Federal do Pampa - Campus São Borja (UNIPAMPA) e no Instituto de Ciências da Sociedade e Desenvolvimento Regional da Universidade Federal Fluminense (UFF). Atualmente é coordenação do Grupo de Trabalho de História Ambiental, GTHA - ANPUH, Brasil e é vice-coordenadora do Laboratório de História Regional e Patrimônio (LAHIRP-UFF), que conta com pesquisadores brasileiros e estrangeiros interessados em discutir a História Regional em sua interseção com a questão patrimonial. Tem experiência na área de História, com ênfase em História Ambiental e História e História Agrária, atuando principalmente nos seguintes temas: migrações, agricultura, rios, paisagem, mata atlântica e pampa.
\end{abstract}

\section{Resumo}

Este artigo versará sobre a questão da Segurança Alimentar e Nutricional e o processo de construção dessa política no Brasil, bem como a questão da cultura alimentar do município de Porto Vera Cruz/RS, efetuando-se uma descrição histórica do município, seus hábitos, costumes e atividades desenvolvidas pela população e pelo governo municipal. A metodologia utilizada para obter os subsídios teóricos que possibilitaram o entendimento da questão proposta baseou-se em fontes de pesquisa bibliográfica e análise de documentos do município. Também foram realizadas reflexões a partir de estudos antropológicos na expectativa de sedimentar algumas noções conceituais que contemplem aspectos da cultura e do contexto histórico e político da Segurança Alimentar e Nutricional. Verificou-se que o incentivo do governo municipal através de políticas públicas auxilia a população na busca da segurança alimentar, que além da produção de alimentos saudáveis para o próprio consumo e oferta de produtos com melhor qualidade para o comércio, ainda revitaliza a cultura através da valorização de tradições locais.

Palavras-chaves: Cultura; Porto Vera Cruz; Segurança Alimentar e Nutricional. 


\title{
FOOD AND NUTRITIONAL SECURITY IN THE HISTORICAL AND CULTURAL CONTEXT OF PORTO VERA CRUZ/RS
}

\begin{abstract}
This article will deal with the question of food and nutritional security and the construction process of this policy in Brazil, as well as the question of the food culture of the municipality of Porto Vera Cruz/RS, making a historical description of the municipality, its habits, customs and activities developed by the population and by the municipal government. The methodology used to obtain the theoretical subsidies that enabled the understanding of the proposed question was based on sources of bibliographic research and analysis of municipality documents. Reflections were also made from anthropological studies in the expectation of sedimenting some conceptual notions that contemplate aspects of the culture and the historical and political context of Food and Nutrition Security. It was found that the municipal government incentive through the public policy assists the population in pursuit of food security, which in addition to the production of healthy food for own consumption and offering products with better quality to the commerce, still revitalizes the culture through the development of local traditions.
\end{abstract}

Keywords: Culture; Food and Nutrition Security; Porto Vera Cruz.

JEL: I150; H70. 


\section{INTRODUÇÃO}

Uma política de Segurança Alimentar e Nutricional (SAN) consiste em um conjunto de ações planejadas pelo governo e sociedade civil organizada, com a finalidade de garantir o acesso aos alimentos para toda a população, objetivando promover a nutrição e a saúde. Esta política deve ser sustentável de forma a articular condições que permitam sua manutenção a longo prazo. Essa política requer um envolvimento intersetorial (saúde, educação, agricultura, desenvolvimento social, meio ambiente...) nas esferas de produção, comercialização, controle de qualidade, acesso e consumo (CONSEA, 2004, p. 4). Ademais, para garantir que a SAN seja sustentável, ela deve agregar componentes econômicos, sociais e principalmente ambientais, pois de acordo com a Conferência das Nações Unidas para o Meio Ambiente e Desenvolvimento (CNUMAD) 3 ocorrida em 1992, foi apontado com clareza que o desenvolvimento e o progresso devem estar em harmonia com a natureza, uma vez que, se todas as pessoas tiverem o mesmo padrão de desenvolvimento dos países ricos, não haverá recursos naturais para todo mundo sem que sejam provocados graves e irreversíveis danos ao meio ambiente. Portanto, os entes administrativos devem receber apoio financeiro e tecnológico que garantam o alcance de um modelo de desenvolvimento que seja sustentável para a segurança alimentar preservando o equilíbrio no planeta no que tange a produção de alimentos (TEIXEIRA, PAGANINE, GUEDES, 2012).

Nesse sentido, a SAN tem como objetivo ações e políticas públicas com natureza estratégica, na medida em que ela orienta opções em vários campos e requer mecanismos e instrumentos permanentes para assegurar sua consecução. A promoção da SAN possui três referências que lhes são inseparáveis: a) direito humano à alimentação adequada; b) soberania alimentar; c) relação com a promoção do desenvolvimento (CERESAN, 2006, p. 21).

No Brasil, o conceito de SAN está estabelecido no art. $3^{\circ}$ da lei 11.346/2006, que consiste na realização do direito de todos ao acesso regular e permanente a alimentos de qualidade, em quantidade suficiente, sem comprometer o acesso a outras necessidades essenciais, tendo como base práticas alimentares promotoras de saúde que respeitem a diversidade cultural e que sejam ambiental, cultural, econômica e socialmente sustentáveis (BRASIL, 2006). 
Segundo Franchikoski e Thomé (p. 127, 2017), no campo da segurança alimentar, as interações entre políticas públicas são relevantes porque envolvem não só a garantia do acesso, mas também a "quantidade suficiente, a qualidade nutricional, a inocuidade, a garantia de produção de alimentos em nível familiar e a garantia do comércio e o respeito à cultura local" (FRANCHIKOSKI; THOMÉ, p. 127, 2017).

Já uma política cultural, entendida habitualmente como programa de intervenções realizadas pelo Estado, instituições civis, entidades privadas ou grupos comunitários, deve prever os caminhos que se pretende traçar para possibilitar que as comunidades criem e desenvolvam suas culturas, buscando satisfazer tanto as necessidades culturais como também promover o desenvolvimento de suas representações simbólicas (COELHO, 1997, p.293). Desta forma, a transversalidade da cultura e a sua importância como instrumento para o desenvolvimento social e econômico das comunidades são questões que devem ser pensadas por aqueles que administram as estruturas governamentais. Segundo o autor, a política cultural apresenta-se como um conjunto de iniciativas que visam promover a produção, a distribuição e o uso da cultura, a preservação e divulgação do patrimônio histórico e o ordenamento do aparelho burocrático por elas responsável.

Faz-se importante destacar que, mais do que uma tarefa administrativa, as políticas devem estimular o debate de ideias, a troca de experiências, os comportamentos e sociabilidades. Essas políticas devem ser elaboradas pensando em garantir à população o direito ao acesso e desfrute dos bens culturais. Mas, além disso, devem possibilitar que todo habitante da cidade se reconheça como sujeito cultural. Devem também incentivar a participação de todos na criação e nas esferas de decisões públicas sobre a cultura, garantindo uma política cultural distanciada dos padrões do clientelismo e da tutela (FARIA, 2003).

Diante do exposto, esse estudo procura discutir aspectos da segurança alimentar, seu contexto histórico e político, bem como discorrer sobre a colonização de Porto Vera Cruz, município situado na fronteira noroeste do Rio Grande do Sul, observando sua cultura e o momento em que o governo passa a se preocupar com a segurança alimentar de seus habitantes, desenvolvendo políticas para a contribuição e o incentivo da agricultura familiar, como também com o resgate e revitalização das tradições culturais locais. 
Justifica-se esse estudo pela relevância de verificar a influência que a cultura exerce na alimentação, buscando relacionar conceitos e contextualizar o modo de vida da população e as atividades desenvolvidas no município. Para compreender claramente o objetivo de pesquisa, far-se-á um breve referencial sobre a Segurança Alimentar e Nutricional (SAN), contextualizando-a política e historicamente; uma conceituação a respeito da cultura, especialmente relacionada à alimentação; e uma apresentação do município de Porto Vera Cruz/RS.

\section{SEGURANÇA ALIMENTAR E NUTRICIONAL: CONTEXTUALIZAÇÃO HISTÓRICA E POLÍTICA}

Historicamente, os humanos adaptaram-se aos mais diferentes habitats e, na direção oposta, também modificaram e "adaptaram" o ambiente e suas necessidades. A mais premente delas foi e continua sendo a alimentação, tornando a segurança alimentar de um grupo fator crítico para sua preservação e reprodução. Assim como é para todos os povos e, não poderia deixar de ser para os povos primitivos, a sobrevivência coletiva dependia da obtenção de alimentos. Segundo Ratzel (1900), a alimentação é a necessidade mais profunda dos seres humanos, como também as necessidades que ela impõe aos indivíduos e grupos no sentido de se apropriar de um espaço, defende-lo e se territorializar para cultivar e produzir. Desta forma, a partir do período Neolítico, nenhuma outra mudança teve tanta influência nas gerações subsequentes quanto a que o antepassado do homem experimentou ao se transformar em pastor e agricultor, deixando assim de depender exclusivamente da caça e do extrativismo para nutrir-se. As exigências do processo de produção e a possibilidade de preservar e armazenar alimentos, ao invés de ter que consumi-los imediatamente, tiveram forte impacto na organização das comunidades. Pela primeira vez, seus integrantes começaram a estocar alimentos e tiveram a necessidade de proteger essa nova riqueza dos predadores e das intempéries (ALENCAR, 2001, p. 138).

A um ritmo cada vez mais rápido, o ser humano foi ampliando sua inteligência aplicada ao seu acervo de conhecimentos. Desenvolviam-se técnicas agrícolas, observavam-se as condições meteorológicas, selecionavam-se as melhores sementes e apareciam os implementos agrícolas. Reforçada sua segurança alimentar, o homem se tornava também menos vulnerável, porque melhor alimentado e protegido (ALENCAR, 2001, p. 138). 
O conceito de segurança alimentar foi constituído a partir do final da Segunda Grande Guerra Mundial (1945), momento em que o aumento da produção de alimentos do planeta cresceu muito além do aumento da própria população mundial e a elevação da oferta de comida, que se deve à Revolução Verde, não foi acompanhada pelo declínio da fome mundial como se prometia. Os alimentos podem estar disponíveis, conforme pode ser registrado pelas estatísticas que a FAO levanta para o mundo de tempos em tempos, entretanto, as populações pobres podem não ter acesso a eles, seja por problema de renda ou devido a outros fatores, como conflitos internos e ação de monopólios (BELIK, 2003, p. 14).

Esse conceito levou a um melhor conhecimento da situação alimentar sob os aspectos de quantidade, qualidade e regularidade no acesso aos alimentos. Belik (2003, p. 14) ressalta o conceito desses aspectos, no sentido de que o acesso aos alimentos diferencia-se da disponibilidade dos alimentos, ou seja, os alimentos podem estar disponíveis, mas não acessíveis às camadas mais pobres da população. A qualidade refere-se a consumir os alimentos com dignidade (sem riscos de contaminação ou apodrecimento); e a regularidade diz respeito ao acesso constante à alimentação (pelo menos três vezes ao dia).

No início da década de 1970, a crise mundial de produção de alimentos levou a Conferência Mundial de Alimentação a identificar que a garantia da segurança alimentar teria de passar por uma política de armazenamento estratégico e de oferta de alimentos, associada ao aumento da produção (HIRAI, 2015, p.3). Neste contexto, teve importância a experiência para aumentar a produtividade de alguns alimentos, associada ao uso de novas variedades genéticas fortemente dependentes de insumos químicos, a chamada Revolução Verde, que, de acordo com Wright (2012), iniciou no México em 1940.

No entanto, pouco tempo depois, na década de 1980, percebeu-se que o aumento da produção de alimentos não resultou na alteração do quadro de fome e pobreza no mundo e no Brasil, ao contrário, foi justamente o período em que aumentou o fosso entre pobres e ricos, evidenciando a necessidade da adoção de medidas estruturais que pudessem propiciar maior equidade no acesso aos alimentos (CONTI, 2009, p. 18).

Na década de 1990, emergiram inúmeras organizações, articulações e redes da sociedade civil com expressivas discussões e incidências sobre as propostas de SAN no Brasil, ao mesmo tempo em que o governo passou a desenvolver algumas políticas públicas voltadas à questão alimentar. Nesse contexto, a noção de Segurança Alimentar assimilou novas contribuições, especialmente vindas das organizações da 
sociedade civil, como, por exemplo, a qualidade dos alimentos, a autonomia sobre as decisões de produção e consumo, o respeito às tradições culturais e aos hábitos alimentares, bem como a preocupação ética com as gerações atuais e futuras, e o manejo dos recursos naturais de forma sustentável em toda a cadeia alimentar (CONTI, 2009, p. 19).

Sob a influência de debates ocorridos em espaços internacionais, especialmente no âmbito das redes de organizações da sociedade civil e da Organização das Nações Unidas para a Alimentação e Agricultura (FAO) $)^{4}$, a Segurança Alimentar incorporou elementos da Nutrição como campo de conhecimento, e os princípios da Soberania Alimentar e do Direito Humano à Alimentação Adequada $(\mathrm{DHAA})^{5}$, que haviam sido relativizados há duas décadas. Estes elementos contribuíram para que a Cúpula Mundial da Alimentação, convocada pela FAO em 1996, definisse a Segurança Alimentar e Nutricional como:

A garantia, a todos, de condições de acesso a alimentos básicos de
qualidade, em quantidade suficiente, de modo permanente e sem
comprometer o acesso a outras necessidades essenciais, com base em
práticas alimentares saudáveis, contribuindo assim para uma
existência digna, em um contexto de desenvolvimento integral da
pessoa, com preservação das condições que garantam uma
disponibilidade de alimentos a longo prazo (FAO, 1996).

Em 1999, o Comitê dos Direitos Econômicos e Sociais das Nações Unidas formulou um documento que definia que "o direito à alimentação adequada é alcançado quando todos os homens, mulheres e crianças, sozinhos, ou em comunidade, têm acesso físico e econômico, em todos os momentos, à alimentação adequada, ou aos meios para a sua obtenção" (Comentário Geral 12, ONU, 1996). O termo adequação refere-se não exclusivamente a um pacote mínimo de calorias e nutrientes, mas também a condições sociais, econômicas, culturais e ambientais para uma sobrevivência digna (CONSEA, 2004, p. 12).

Esse documento transformou-se em um marco para as organizações de direitos humanos e para toda a comunidade internacional. O documento propõe expressamente em seu parágrafo 15 : 
Sempre que um indivíduo ou grupo é incapaz, por razões além de seu controle, de usufruir o direito à alimentação adequada com recursos à sua disposição, os Estados teriam a obrigação de realizar (prover) tal direito diretamente. Esta obrigação também deve existir no caso de vítimas de desastres naturais ou provocados por causas diversas (PESSANHA, 2001, p. 43).

Portanto, o direito de se alimentar regular e adequadamente não deve ser resultado de ações de caridade, mas sim, uma obrigação a ser exercida pelo Estado. Para a garantia do DHAA, o Estado precisa estabelecer políticas que melhorem o acesso das pessoas aos recursos para produção ou aquisição, seleção e consumo de alimentos. Essa obrigação se concretiza através da elaboração e efetivação de políticas, programas e ações que promovam a realização do direito humano à alimentação para todos, definindo metas, prazos, indicadores, e recursos alocados para tal fim (HIRAI, 2015, p. 5).

É por meio da Política de Segurança Alimentar e da Soberania Alimentar ${ }^{6}$ articulada a outros programas e políticas públicas que o Estado deve respeitar, proteger, promover e prover o DHAA. Os principais conceitos empregados na definição de Direito Humano à Alimentação Adequada são: disponibilidade de alimentos, adequação, acessibilidade e estabilidade do fornecimento (BURLANDY, 2010).

De acordo com Valente (2004), a promoção do DHAA demanda a realização de:

Ações específicas para diferentes grupos e passa pela promoção da reforma agrária, da agricultura familiar, de políticas de abastecimento, de incentivo a práticas agroecológicas, de vigilância sanitária dos alimentos, de abastecimento de água e saneamento básico, de alimentação escolar, do atendimento pré-natal de qualidade, da não discriminação de povos, etnia e gênero, entre outros (VALENTE, 2004, p. 27-28).

Uma política de SAN deve equacionar a questão da produção agroalimentar no Brasil, levando-se em conta os aspectos socioeconômicos, culturais e ambientais associados à produção. De acordo com a II Conferência Nacional de Segurança Alimentar e Nutricional (CONSEA, 2004, p. 7), as políticas de estímulo ao crescimento da produção agroalimentar, importante para a segurança alimentar e para a exportação, devem estar associadas a itens como: 
- Promoção de formas socialmente equitativas e ambientalmente sustentáveis de ocupação do espaço agrário;

- Valorização das culturas alimentares locais e regionais;

- Enfrentamento da pobreza rural, já que são nas áreas rurais que se localizam os mais elevados índices de pobreza e de insegurança alimentar;

- Estímulo ao desenvolvimento local e regional. O apoio aos pequenos e médios produtores rurais e urbanos de alimentos promove a equidade e a inclusão social, pois são grandes geradores de ocupação e de renda, ao mesmo tempo que resulta em maior e mais diversificada oferta de alimentos de qualidade à população, produzidos sob formas sustentáveis (CONSEA, 2004, p. 7).

Faz-se importante destacar que a soberania alimentar procura dar importância à autonomia alimentar dos países e está associada à geração de emprego e à menor dependência das importações e flutuações de preços do mercado internacional (Maluf, 2000, p. 59). Além disso, atribui uma grande importância à preservação da cultura e aos hábitos alimentares de um país (BELIK, 2003, p. 14).

O princípio da soberania alimentar ampara o direito dos povos de definirem estratégias próprias para a produção e o consumo dos alimentos, as quais contribuem para o exercício soberano de políticas de SAN. Dentre as estratégias destacam-se as ações que promovem a aproximação entre produção e consumo de alimentos de qualidade, ao mesmo tempo em que valorizam a diversidade dos recursos naturais, produtos e hábitos alimentares (CERESAN, 2006, p. 22).

Nesse sentido, a SAN passa a representar um dos eixos ordenadores das estratégias de desenvolvimento de um país, sugerindo formas mais equitativas e sustentáveis de produzir e comercializar os alimentos, questionando o padrão de consumo alimentar e requalificando as ações dirigidas para os grupos sociais mais vulneráveis à fome, à desnutrição e aos demais problemas nutricionais. As ações e políticas públicas de SAN participam, portanto, da difícil tarefa de associar dinamismo econômico, promoção de equidade social e melhoria sustentável da qualidade de vida (CERESAN, 2006, p. 22). 


\section{IDENTIDADE CULTURAL E ALIMENTAÇÃO}

O conceito de cultura é polissêmico, utilizado para se referir aos costumes e hábitos de um povo, às diferentes maneiras de expressão artística, a um modo da civilização e aos saberes produzidos por um determinado grupo. De acordo com Eagleton (2011, p.9) a "cultura é considerada uma das duas ou três palavras mais complexas de nossa língua [...]." Mais complexa do que o termo cultura, para o autor, somente o termo "natureza", que é o seu oposto.

Conforme explica Duarte e Martins (2012), cultura é a atividade humana acumulada, a qual envolve a ação do ser humano e sua relação com a natureza com o objetivo de produzir sua existência. Definindo etimologicamente, cultura significa: lavoura, cultivo, ou seja, é um elemento que deriva da natureza, de sua transformação pela ação humana.

Segundo Laraia (1986, p. 20), o comportamento do indivíduo depende de um aprendizado de unir processos que chamamos de endoculturação. Pensando que a cultura condiciona a visão de mundo do homem na sociedade, é importante mencionar a antropóloga Ruth Benedict (1972) que em seu livro O crisântemo e a espada, afirma que a cultura é como uma lente através da qual o homem vê o mundo. Homens de culturas diferentes usam lentes diversas e, assim, têm visões desencontradas das coisas. Geertz (1989) questiona o que seria a cultura, porém ele diz que se deve perguntar qual a sua importância. Cultura é uma realidade com força e propósitos em si mesma. Ela consiste em um padrão de acontecimentos comportamentais que se observa em uma comunidade identificável. $\mathrm{O}$ autor comenta sobre a etnociência, na qual a cultura é composta por estruturas psicológicas, por meio das quais os indivíduos ou grupos guiam seu comportamento, sendo:

[...] a cultura é mais bem vista não como complexos de padrões concretos de comportamento-costumes, usos, tradições, feixes de hábitos, mas como um conjunto de mecanismos de controle- planos receitas, regras, instruções, o que os engenheiros de computação chamam "programas" (GEERTZ, 1989, p.56).

Assim, segundo Geertz (1989), a cultura não deve ser considerada apenas o conjunto de hábitos e tradições de um grupo, mas um programa, planos, regras, instruções e simbologias que orientam o comportamento. Essas reflexões são úteis para entender o ser humano, que se completa dentro de processos sociais específicos e se torna produtor de modos de produzir. 
Sob este prisma, os alimentos podem ser interpretados como sínteses ancestrais de técnicas, símbolos e significados, produção material e intelectual da vida, ou, como destaca Montanari (2008), sempre cultura, nunca apenas pura natureza. Neste contexto, as práticas alimentares de um determinado grupo na sociedade são particulares e específicas, conforme as características que ele apresenta. Nem todos os grupos vivem da mesma forma, nem todos comem da mesma forma e se alimentam das mesmas coisas. No momento em que se compartilha a alimentação em volta de uma mesa, além de se alimentar para satisfazer necessidades biológicas, está-se compondo e recompondo a sua cultura.

Cada sociedade estabelece um conjunto de práticas alimentares, as quais expressam diferentes culturas, algumas ligadas ao que é tradicional e outras ao que é inovador. Algumas não se fixam, desaparecendo pouco a pouco. Outras se enraízam, vindo a formar hábitos alimentares, consolidando-se ao longo do tempo e, em muitos casos, constituindo-se em patrimônio cultural. As tradições alimentares de cada grupo social têm importância no seu auto reconhecimento e autoestima, expressando ou afirmando determinado valor, o qual se configura em peculiaridades locais (CONSEA, 2004, p. 61).

CONSEA (2004, p. 61) nos traz a informação de que nas Américas, as diferentes expressões de culturas alimentares estão fortemente relacionadas às populações que se deslocaram para cá, pois cada uma trouxe hábitos e necessidades diferentes, grande variedade de alimentos e temperos e ali incluídas suas preferências. As influências dessas populações representam importantes contribuições que se somaram a uma cultura já consolidada. Elas confrontaram sistemas alimentares diversos e foram introduzidas em um contexto de colonização, entre povos diferentes.

É constante a afirmação de que a culinária brasileira é o resultado das influências portuguesa, negra e indígena. De fato, esta é a base principal da cultura alimentar brasileira, mas não se pode deixar de considerar que a influência da cozinha portuguesa se deu no contexto de colonização em que os africanos eram escravos e os indígenas estavam sendo dizimados (CONSEA, 2004, p. 61).

Além disso a caracterização da cultura alimentar brasileira deve considerar a dimensão continental do país, não apenas em seus aspectos físicos, mas na própria diversidade de condições históricas de apropriação e colonização de seu território. O Brasil tem culturas alimentares diversas em cada uma de suas regiões, com pratos típicos que são marcadores de identidade. Ainda, ao lado da influência de portugueses, negros e indígenas, estão as famílias italianas, alemãs, espanholas, polonesas, japonesas e árabes, entre outras, que se estabeleceram em regiões específicas pelo país, introduzindo seus hábitos 
alimentares. Por fim, devem ser considerados os fatores ambientais (clima, tipo de solo, disposição geográfica, a fauna e a flora de cada região) e sua influência nas condições de existência e capacidade de acesso dos diferentes grupos sociais aos alimentos. Tudo isto faz com que a cozinha brasileira expresse uma multiplicidade de culturas regionais (CONSEA, 2004, p. 61).

A cultura alimentar é um patrimônio valioso que precisa ser preservado. Para isso, um primeiro passo é criar as condições para que a sociedade conheça sua história agrícola e alimentar, valorizando esse patrimônio enquanto tal. Só assim poderá perceber que os hábitos alimentares de seus antepassados traduzem sua própria identidade (CONSEA, 2004, p. 63).

É importante ainda compreender que a preservação da cultura alimentar deve estar associada a processos relativos à garantia das condições de segurança alimentar para a população. O direito de todas as pessoas terem acesso aos alimentos somente será assegurado por meio da plena condição de aquisição e produção desses alimentos. Isto permite que o consumidor faça suas escolhas, sem o constrangimento de se defrontar com custos que não pode assumir ou de se ver obrigado a consumir alimentos que não correspondem a seus hábitos e tradições (CONSEA, 2004, p. 63).

\section{PORTO DE VERA CRUZ: REVITALIZAÇÃO HISTÓRICA E CULTURAL}

Porto Vera Cruz é um município localizado no Noroeste do Estado do Rio Grande do Sul, banhado pelas águas do rio Uruguai com fronteira fluvial com a Argentina a oeste, Santo Cristo a leste, Alecrim a norte e Porto Lucena a Sul. Tem uma extensão de $112 \mathrm{~km}^{2}$ e dista $600 \mathrm{~km}$ da capital Porto Alegre.

A colonização de Porto Vera Cruz iniciou por volta de 1910. Consta que os primeiros colonizadores (alemães, poloneses, italianos e russos) vieram de seus países de origem, chegando pelo Rio Uruguai de caíque $^{7}$ e canoa, em função das atividades comerciais que eram exercidas via este rio. Essa colonização se projetou sobre o atual território do município, derrubando matos entrelaçados e ali construindo seus ranchos nas proximidades das barrancas. No entanto, o maior afluxo de colonizadores deu-se a partir de 1920, até meados de 1940. Antes dos colonizadores, os primeiros habitantes foram os índios Guaranis, povoadores das encostas do Rio Uruguai. Por outro lado, elementos humanos provindos da República Argentina fixaram-se nesta zona limítrofe. Em 1943, quando o comércio começou a expandir-se no atual território do município, vieram habitantes oriundos de Cerro Largo, Santo Cristo e posteriormente de Santa Rosa. 
Em 1990 iniciaram os movimentos emancipacionistas objetivando autonomia política para o desenvolvimento local. Isso deveu-se porque o município polo, na época Porto Lucena, mostrava dificuldades na aplicação de recursos para estas localidades mais distantes. Desta forma, líderes locais se reuniram, formaram a Comissão Emancipatória e foram em busca desta conquista, acontecendo a emancipação política e administrativa em 1992 através da lei $\mathrm{n}^{\circ} 9.588$ de 20 de março de 1992. A instalação aconteceu dia $1^{\circ}$ de janeiro de 1993. O município desmembrou-se dos municípios de Porto Lucena, Alecrim e Santo Cristo.

Sua população é de 1.851 habitantes (IBGE, censo 2010), sendo que 1.411 residem no meio rural e 440 no meio urbano. A etnia alemã é predominante na colonização do município, seguida por brasileiros natos, poloneses, italianos e russos (Secretaria de Educação e Cultura - Porto Vera Cruz) ${ }^{\underline{8}}$.

O clima predominante é o subtropical úmido com temperatura média de $20^{\circ} \mathrm{C}$, sendo a média das máximas $27^{\circ} \mathrm{C}$ e a média das mínimas $7^{\circ} \mathrm{C}$, com precipitação anual entre 1.650 a $1.950 \mathrm{~mm}$, porém mal distribuídos com concentração nos meses de fevereiro, setembro e outubro, com déficit nos meses de dezembro e janeiro. O relevo apresenta declividade no sentido do Rio Uruguai e solos com afloramento de rochas. Nesse contexto, verificou-se ao longo dos anos a insustentabilidade de culturas anuais, como soja e trigo (BÁRBARO, 2012).

Em seu estudo, Bárbaro (2012) relata que nos últimos anos ocorreram com grande frequência eventos climáticos prejudiciais, afetando economicamente o município. Estiagens severas, principalmente no verão, causaram perdas significativas no setor primário. Temporais com chuvas fortes associadas a queda de granizo e vendaval danificaram não somente lavouras, mas também imóveis, com queda de árvores e postes de iluminação pública. Enchentes nas várzeas causaram falta de pasto para o gado e perdas nas lavouras de milho e soja.

Atualmente, a zona rural do município tem a nítida caracterização de êxodo rural, pela quantidade de imóveis vendidos, geralmente devido à impossibilidade da permanência, uma vez que não visualizam uma perspectiva de melhoria na qualidade de vida. Na esperança de oportunizar aos descendentes o estudo para a profissionalização, no intuito de livrá-los da penosidade do trabalho rural, muitas famílias transferiram suas residências para a área urbana, inclusive para outros municípios maiores, mais perto da capital gaúcha, as quais oportunizam mais empregos. Outros não conseguiram acompanhar as mudanças tecnológicas da lavoura, por desinformação ou falta de capital de giro, ou ainda por terem as áreas 
produtivas esgotadas química e fisicamente devido a cultivos que exigiram uso de produtos e maquinários que provocaram alterações prejudiciais ao solo, uma vez que não ocorreram análises ou estudos de impacto ou de adequação para determinados plantios ou cultivos. Desta forma, optaram por mudar de profissão ou prestar serviços como mão-de-obra, na zona urbana do município e até mesmo em municípios vizinhos, em detrimento de sua propriedade. Adolescentes rurais foram atraídos pela mídia visual e falada e procuraram grandes centros para trabalharem, principalmente as regiões da serra e a capital, com pouca possibilidade de retorno ao campo.

A busca por alternativas mais viáveis economicamente e com melhores manejos do solo, aliada ao microclima do Vale do Rio Uruguai, fez com que cooperativas e entidades desenvolvessem estudos e pesquisas sobre possibilidades de produção mais viáveis, através de uma mudança na matriz produtiva.

No ano de 1984, iniciou-se um programa de introdução à fruticultura tropical na região noroeste do estado, através de um convênio entre a EMATER/RS-ASCAR, a Cooperativa Tritícola Santa Rosa (COTRIROSA) e a Universidade Federal do Rio Grande do Sul (UFRGS), para desenvolver atividades de pesquisa e extensão rural com as culturas de abacate, abacaxi, banana, goiaba, mamão, manga e maracujá. Um dos motivos para o desenvolvimento da pesquisa se deu pela existência de condições climáticas favoráveis na região costeira do rio Uruguai. Este trabalho foi desenvolvido no Centro de Pesquisa e Extensão em Fruticultura Tropical (CEPEX), na localidade de Linha Roncador, na época pertencente ao município de Porto Lucena e, atualmente, pertencente a Porto Vera Cruz (BÁRBARO, 2012).

O programa tinha por objetivo oferecer uma nova alternativa de emprego e renda para as propriedades familiares, na época com atividades voltadas basicamente para a produção de culturas anuais (milho, soja e fumo). O projeto ainda tinha como intuito melhorar as condições socioeconômicas das famílias. Desta forma, a ideia seria diminuir o êxodo rural, melhorar o abastecimento do mercado local com frutas tropicais e utilizar culturas permanentes nas áreas declivosas próximas ao rio Uruguai.

Apontou-se que os frutos produzidos nessa região são considerados em geral mais doces e a produção é antecipada em relação à maioria das outras regiões do estado, resultado da combinação do tipo de solo e microclima. Essa mudança na matriz produtiva no município vem acontecendo gradativamente desde 2001, com diversidade de frutas como uva, melão, melancia, laranja, amora preta, abacaxi e goiaba. Isso contribuiu para o empoderamento dos agricultores, que formaram a Cooperativa 
de Agricultores de Porto Vera Cruz (COOPOVEC) ${ }^{9}$, onde tencionam o planejamento da produção, manejo e busca conjunta de canais de comercialização, destacando os mercados institucionais, como o Programa de Aquisição de Alimentos (PAA) $\frac{10}{}$ e o Programa Nacional de Alimentação Escolar $(\mathrm{PNAE})^{11}$ (BÁRBARO, 2012).

O crescimento da fruticultura de Porto Vera Cruz elevou a atividade para uma importante condição em termos quantitativos, fazendo-se perceber sua importância como atividade econômica para os agricultores, assim como as diferentes formas assumidas a partir da organização dos produtores, das instituições de apoio e das relações com o mercado.

$\mathrm{O}$ município estabeleceu como política pública o incentivo à fruticultura, criando diversos mecanismos transformados em leis municipais, tais como a disponibilização de linhas de crédito (financiamentos de investimento, equalização de juros, custeio para capacitação), serviços de máquinas, serviços especializados (carpinteiros para instalação da estrutura de sustentação dos parreirais), assistência técnica e fornecimento de rótulos e embalagens.

A atividade da fruticultura tem incentivo da EMATER-RS/ASCAR, Prefeitura Municipal, Embrapa e COOPEVEC, para que os agricultores façam investimentos e garantam alternativas de emprego e renda, aproveitando as condições climáticas favoráveis para a atividade. As políticas públicas são para os fruticultores uma forma de incentivo para iniciar uma nova atividade sem tradição para a maioria das famílias; um incentivo para investir em novas alternativas, melhorando a renda, melhorando a qualidade de vida e a autoestima das famílias rurais.

No que se refere ao campo da SAN, as ações locais (municipais) vêm ganhando importância no Brasil. Na esfera municipal, fíca mais evidente a atuação das entidades da sociedade civil, assim como se verifica uma relação mais próxima entre as instâncias propositoras de políticas e a execução das ações correspondentes, comparativamente, ao que se verifica na esfera federal (CERESAN, 2006, p. 31). É no nível municipal que as urgências alimentares se manifestam sob a forma de demanda direta e imediata, dando origem a ações governamentais e não-governamentais. Um levantamento de experiências significativas de ações públicas locais de SAN (COSTA; MALUF, 2001, p. 16) constatou que os municípios são capazes de tomar iniciativas relevantes nas quatro dimensões da SAN, a saber: apoio à produção agroalimentar equitativa e sustentável; abastecimento alimentar; consumo e educação alimentar; programas dirigidos a grupos populacionais específicos. Assim, é possível criar nos 
municípios espaços institucionais ou organismos articuladores de ações Intersetoriais e em parceria entre os governos e a sociedade civil, coordenadas por uma política municipal de SAN institucionalizada (CERESAN, 2006, p. 32).

A evolução da política agrícola, com programas favoráveis à agricultura familiar, está influenciando a permanência de pequenos produtores no campo e trazendo inovadores urbanos para a área rural, inclusive despertando o interesse de alguns jovens para a sucessão familiar, por acreditarem na profissionalização das atividades rurais e obterem ganhos compensadores para terem qualidade de vida e as comodidades urbanas ofertadas pela informatização e globalização, sem saírem do interior. Conforme citam Espeiorin e Pozenato (2010), a globalização, alicerçada nos meios de comunicação, possibilita alterações socioeconômicas e culturais, transformando o meio rural através de modificações ocasionadas por novas tecnologias, as quais são empregadas no cultivo e produção rural.

Nesta direção, o papel da pequena produção ganha novos atributos diante de mudanças na organização econômica e institucional do sistema agroalimentar. Segundo Wilkinson (2003), os produtos e as práticas tradicionais; aquelas exercidas em pequenas propriedades, normalmente sendo a policultura, que utiliza-se de técnicas rudimentares, artesanais e ancestrais e que têm como prioridade a subsistência das famílias que a praticam, podem ser promotores de estratégias de produção sustentável.

Cabe destacar que com a criação da cooperativa, houve a possibilidade de revitalizar as atividades agrícolas e incentivar o cadastro de pequenos agricultores. Hoje a COOPEVEC conta com 76 produtores que comercializam junto aos programas institucionais do Governo Federal (Programa Nacional da Alimentação Escolar - PNAE e o Programa de Aquisição de Alimentos - PAA), no mercado em geral e na feira municipal. Vale ainda ressaltar que existe a incipiente presença da agroindústria para o beneficiamento e processamento das frutas, abrindo a possibilidade da industrialização de sucos, geleias, compotas e vinhos.

Segundo Trichês (2012), quando se trata da alimentação saudável, se está diante de processos de qualificação e requalificação de alimentos domésticos, em contraposição aos industrializados. A tendência de qualificação segue uma lógica de ação dos atores para atingir seus projetos coletivos ou individuais, construindo complexas e inter-relacionadas práticas e incorporando valores sociais aos produtos. Nesta questão, o enraizamento nos mercados locais, os valores sociais e a localização amparariam novas visões de qualidade que beneficiariam a escala local, em detrimento dos valores 
disseminados pela escala global (TRICHÊS, 2012). A ideia de valorização e novas visões de qualidade que beneficiariam a escala local são as visões que apontam que a nova agricultura familiar não necessariamente precisa ser rústica, ela pode usar da sua proximidade com a informatização e se qualificar, se especializar, agregar qualidade aos seus produtos sem perder a especificidade de ser um produto local regional, produzido em uma pequena propriedade de agricultura familiar.

A produção alimentar desenvolvida fez com que os fruticultores, juntamente com o governo municipal, organizassem a Festa das Frutas. Cada ano, no mês de dezembro, quando acontece o auge da produção de frutas (uva, melão, melancia), é realizado esse evento, ocasião em que são trazidas para degustação e comercialização as mais diversas espécies de frutas para a sede do município.

Também preocupado em valorizar a história, cultura e tradição, em 2009 o governo municipal lançou a ideia para que as comunidades do município se organizassem na realização de encontros e festas de suas etnias. E até hoje, anualmente, as localidades interioranas se esforçam para manter as tradições. As festas italiana, polonesa e alemã proporcionam diversão, oferecendo alimentos tradicionais de cada cultura, os quais são cultivados e produzidos nas próprias comunidades de descendentes. Além disso, ainda apresentam danças típicas, vestimentas e música. Além destas, o município também realiza anualmente o jantar do peixe, evento organizado pela EMATER, no qual são servidos diversos pratos, todos à base de peixe, uma vez que a pesca é atividade rotineira no município, pelo fato de ser banhado pelo rio Uruguai.

Segundo Flandrin e Montanari (1996), as comidas típicas são elementos que valorizaram a cultura regional, as quais perpetuam a memória culinária das famílias e são capazes de oferecer ganhos econômicos, tanto para a indústria como para o comércio local. Desta forma, a Gastronomia Típica de uma região permite simbolizar uma cultura.

A tradição, a história, os sabores, as técnicas e as práticas culinárias somadas contribuem para a formação das culturas regionais. Observa-se uma tendência da sociedade à valorização patrimonial de sua cozinha, bem como o resgate da culinária tradicional em várias partes do mundo, ocorrendo, então, a revalorização das raízes culturais (BELUZZO, 2004, p. 242). Dentro deste tema, Lody (2004, p. 150) e Canesqui (2005, p. 36), enfatizam que comer é antes de tudo um ato simbólico, tradutor de sinais, de reconhecimentos formais, de cores, de texturas, de temperaturas, entre outros. Consiste num ato que une memória, desejo, fome, significado, sociabilidade e ritualidade. 
Os modos alimentares se articulam com outras dimensões sociais e com a identidade. O valor cultural do ato e do modo alimentar é cada vez mais entendido enquanto patrimônio, pois a comida é tradutora de povos, nações, civilizações, grupos étnicos, comunidades e famílias. Entendendo a estrutura culinária como o conjunto de regras e normas relacionadas à alimentação, incluindo os alimentos escolhidos, a organização do cardápio, as técnicas de preparo e os temperos, é possível identificar a culinária de uma região ou nação como uma particularidade cultural (GARCIA, 1999, p. 14). Neste sentido, a revitalização das culturas locais significou um retorno à alimentação tradicional das etnias e sua propagação para as novas gerações.

Cada cultura possui uma gastronomia peculiar, com receitas, ingredientes, técnicas de preparação, maneiras de servir, de comer, até mesmo de colher, produzir, conservar e consumir. E neste sentido, em Porto Vera Cruz, a comunidade responsável pela festa étnica se empenha na elaboração de tudo que envolve os pratos típicos, produzindo todos os ingredientes que serão utilizados no preparo. Ginani (2005) afirma que as receitas regionais são conhecidas e valorizadas por comporem os hábitos alimentares nativos, sendo elaboradas com os ingredientes disponíveis na região e preparadas com técnicas transmitidas de geração a geração.

Garcia (1999) destaca que desde as etapas de preparação até o consumo, estão inclusos vários fatores culturais que compões as identidades dos atores envolvidos, pois as elaborações típicas não se limitam somente a receitas diferentes, mas envolvem ingredientes, métodos, preparações, formas de sociabilidade e sistemas de significados que se baseiam, sobretudo, na experiência vivida. Quando uma comida se torna típica em uma localidade é porque já faz parte de sua cultura. Pode-se perceber uma valorização dos sabores pertencente aos elementos nativos da região, produzidos pelo pequeno produtor com peculiaridades geoclimáticas, em conformidade com padrões artesanais.

Por fim, as práticas alimentares de uma nação não decorrem somente do mero instinto de sobrevivência ou do prazer do homem em se alimentar, mas expressam sua história, geografia, clima e organização social, podendo ser incluída no rol de bens que compõem os chamados Patrimônios Imateriais ou Patrimônios Intangíveis.

Como vimos, o município em questão possui incentivos governamentais para a busca e garantia da Segurança Alimentar e preservação de sua cultura alimentar local. Exemplo disso é a prática de cultivos próprios ao clima e solo e a revitalização de culturas étnicas. Ademais, o jantar do peixe, por si só, já 
representa a cultura intangível, por ser um alimento próprio do local, o qual agrega valor em pratos preparados, como por exemplo a lasanha de peixe, pastel de peixe, e muitas outras formas de preparo que são oferecidos no evento.

\section{CONSIDERAÇÕES FINAIS}

A Segurança Alimentar e Nutricional expressa um direito de toda a população, tem natureza estratégica e deve ser buscada de forma permanente com base no exercício de políticas soberanas. Essa concepção permite afirmar que há uma questão alimentar nos processos de desenvolvimento e que pode contribuir com a promoção da equidade social e a melhoria sustentável da qualidade de vida da população.

Levando-se em conta todos os aspectos aqui explanados, constata-se com este estudo que, através da promoção de formas socialmente equitativas e ambientalmente sustentáveis de ocupação do espaço agrário, o município em estudo demonstra a preocupação com a SAN de sua população, garantindo estímulo ao desenvolvimento local, apoio aos agricultores, geração de ocupação e renda, equacionando assim a questão da produção agroalimentar, levando em conta os aspectos socioeconômicos, culturais e ambientais associados à produção.

O governo municipal, através do incentivo à fruticultura e criação de mecanismos como disponibilização de linhas de crédito, serviços especializados e assistência técnica tem auxiliado a população na busca da produção de alimentos saudáveis para o próprio consumo e oferta de produtos com melhor qualidade para o comércio. Essas políticas públicas são para os fruticultores uma forma de incentivo para investir em novas alternativas, melhorando a renda, melhorando a qualidade de vida e a autoestima das famílias rurais. Como destacado anteriormente, isso pode ser percebido na efetivação da feira do produtor rural, na organização da cooperativa e com as vendas dos produtos para o programa de alimentação escolar.

No tocante à temática abordada sobre a cultura alimentar, Porto Vera Cruz demonstra sua peculiaridade pelos traços da colonização. $\mathrm{O}$ ato de se alimentar torna-se a expressão e a característica da comunidade, que tem incentivo governamental para manter sua cultura alimentar cultivada e preservada através da revitalização e valorização das tradições locais, o que se percebe com a organização das comunidades para as festas das etnias e o jantar do peixe, como descrito anteriormente. 
Concluindo, vale reiterar a necessária expansão e interação de políticas públicas, garantindo bases sustentáveis ao desenvolvimento da agricultura, enraizamento da cultura e tradições e consequentemente, da SAN.

\section{Referências}

ALENCAR, Álvaro Gurgel de. Do conceito estratégico de segurança alimentar ao plano de ação da FAO para combater a fome. Revista Brasileira de Política Internacional, Brasília, vol.44, no.1, p. 137-144, Jan./Jun. 2001. Disponível em https://goo.gl/XGr4Yv. Acessado em: 03 out. 2016.

BÁRBARO, Gilberto J. Relato de experiência sobre a fruticultura em Porto Vera Cruz. Trabalho de Conclusão do Curso de Tecnólogo em Agricultura Familiar e Sustentabilidade, Centro de Ciências Rurais da Universidade Federal de Santa Maria (UFSM, RS). Santa Maria (RS). 2012.

BELIK, Walter. Perspectivas para a segurança alimentar e nutricional no Brasil. Revista Saúde e Sociedade. São Paulo, v.12, n.1, p.12-20, jan-jun 2003. Disponível em https://goo.gl/XdT04X Acessado em: 03 out. 2016.

BELUZzO, Rosa. A Valorização da Cozinha Regional. In: $1^{\circ}$ Congresso Brasileiro de Gastronomia e Segurança Alimentar, Brasília - DF. Coletânea de palestras. Brasília. 2004.

BENEDICT, Ruth. O crisântemo e a espada. São Paulo: Editora Perspectiva. 1972.

BRASIL. Fundo Nacional de Desenvolvimento da Educação (FNDE). Sobre o PNAE. Disponível em https://goo.gl/ymi4lk Acessado em: 18 out. 2016.

BRASIL. Lei $\mathrm{n}^{\circ}$. 11.346 de 15 de setembro de 2006. Cria o Sistema Nacional de Segurança Alimentar e Nutricional (SISAN) com vistas em assegurar o direito humano à alimentação adequada e dá outras providências. Disponível em: https://goo.gl//ksHaF. Acessado em: 30 out. 2016.

BRASIL. Ministério do Desenvolvimento Agrário (MDA). Sobre o Programa PAA. Disponível em http://www.mda.gov.br/sitemda/secretaria/saf-paa/sobre-o-programa Acessado em: 01 out. 2016.

BURLANDY, Luciene; MALUF, Renato. Soberania Alimentar. In: CONSELHO NACIONAL DE SEGURANÇA ALIMENTAR E NUTRICIONAL. A Segurança Alimentar e Nutricional e o Direito Humano à Alimentação Adequada no Brasil. Indicadores e monitoramento, da Constituição de 1998 aos dias atuais, 2010. Disponível em: https://goo.gl/wQwJuS. Acesso em: 09 out. 2016.

CANESQUI, Ana Maria. Comentários sobre os Estudos Antropológicos da Alimentação. In: CANESQUI, Ana Maria; GARCIA, Rosa Wanda Diez. Antropologia e Nutrição: um diálogo possível. $1^{\circ}$ Ed. Rio de Janeiro: FIOCRUZ. 2005. 


\section{CENTRO DE REFERÊNCIA EM SEGURANÇA ALIMENTAR E NUTRICIONAL (CERESAN).}

Construção e promoção de sistemas locais de segurança alimentar e nutricional: aspectos produtivos, de consumo, nutricional e de políticas públicas. Relatórios Técnicos, 3. CPDA. UFRRJ: Rio de Janeiro. 2006.

COELHO, Teixeira. Dicionário crítico de política cultural. São Paulo: Editora Iluminuras. 1997.

CONSELHO NACIONAL DE SEGURANÇA ALIMENTAR E NUTRICIONAL (CONSEA). Princípios e Diretrizes de uma Política de Segurança Alimentar e Nutricional. Textos de Referência da II Conferência Nacional de Segurança Alimentar e Nutricional. Brasília, Julho de 2004. Disponível em https://goo.gl/j7Wx6C Acessado em: 03 de outubro de 2016.

CONTI, Irio Luiz. Segurança Alimentar e Nutricional: noções básicas. Passo Fundo/RS: IFIBE. 2009.

COSTA, Christiane G.; MALUF, Renato Sérgio. Diretrizes para uma política municipal de segurança alimentar. São Paulo: Instituto Pólis, 2001.

CRUZ, Fabiana T.; SCHNEIDER, Sergio. Qualidade dos alimentos, escalas de produção e valorização de produtos tradicionais. Revista Brasileira de Agroecologia, Pelotas/RS, v.5, n.2, p. 22-38 (2010). Disponível em https://goo.gl/WPGU6K Acesso em: 15 out. 2012.

DUARTE, Newton; MARTINS, Ligia Márcia. As contribuições de Aleksei Nikolaevich Leontiev para o entendimento da relação entre educação e cultura em tempos de relativismo pós-moderno. Texto inédito, 2012.[mimeo]

EAGLETON, Terry. A ideia de cultura. 2a ed. São Paulo: Editora UNESP. 2011.

ESPEIORIN, Vagner Adilio; POZENATO, Kenia Maria Menegotto. Globalização, Meios de Comunicação e Zona Rural: as transformações culturais no interior do Rio Grande do Sul. Trabalho apresentado ao IJ 7, na divisão temática Comunicação, Espaço e Cidadania, do Intercom Júnior, no XI CONGRESSO DE CIÊNCIAS DA COMUNICAÇÃO NA REGIÃO SUL e realizado de 17 a 19 de maio de 2010.

FAO. ORGANIZAÇÃO DAS NAÇÕES UNIDAS PARA A AGRICULTURA E ALIMENTAÇÃO. Alimentação para todos. Cimeira Mundial da Alimentação, Roma. 1996.

FAO no Brasil - Memória

de Cooperação Técnica, 2009. Disponível em: https://goo.gl/vW4N1x. Acesso em: 17 dez. 2016.

FARIA, Hamilton. Políticas públicas de cultura e desenvolvimento humano nas cidades. In: BRANT, Leonardo (org). Políticas Culturais. Vol. 1. Barueri: Manole. 2003.

FLANDRIN, Jean-Louis; MONTANARI, Massimo. A história da alimentação. Paris: Ed. Fayard. 1996. 
FRANCHIKOSKI, Sandra Cristina; THOMÉ, Carlos. Preocupações internacionais com segurança alimentar e nutricional: o papel da FAO. Revista Intellector, Rio de Janeiro, v. 14, n. 27, 2017. Disponível em: http://www.cenegri.org.br/intellector/ojs2.4.3/index.php/intellector/article/view/147/103. Acesso em: 03 maio 2018.

GARCIA, Rosa Wanda Diez. A Comida, a Dieta o Gosto. Mudanças na Cultura Alimentar Urbana. 305 f. Tese (Doutorado em Psicologia) - Universidade de São Paulo. São Paulo-SP, 1999.

GEERTZ, Clifford. A Interpretação das Culturas. Rio de Janeiro: LTC. 1989.

GINANI, Verônica Cortês. Índice de Aceitação de Preparações Regionais com Teor Lipídico Reduzido. Dissertação (Mestrado em Nutrição Humana). Universidade de Brasília. Brasília-DF, 2005.

HIRAI, Wanda Griep; SILVA, Elyda Vilela da; MAIA, Jéssica Laís Batista. Segurança alimentar e nutricional: a cultura alimentar da população quilombola. VII Jornada Internacional de Políticas Públicas. Cidade Universitária da UFMA, São Luís-MA. 2015.

INSTITUTO BRASILEIRO DE GEOGRAFIA E ESTATÍSTICA (IBGE). Censo 2010. Disponível em: http://www.ibge.gov.br/home/ Acessado em 15 de julho de 2016.

LARAIA, Roque de Barros. Cultura: um Conceito Antropológico. Rio de Janeiro: ZAHAR. 1986.

LODY, Raul. Comer é pertencer. In: $1^{\circ}$ Congresso Brasileiro de Gastronomia e Segurança Alimentar, Brasília-DF. Coletânea de palestras. Brasília, 2004.

MALUF, Renato Sérgio. O Novo contexto internacional do abastecimento e da segurança alimentar. In: Belik, W \& Maluf, R. Abastecimento e Segurança Alimentar. Campinas: Unicamp. 2000.

MONTANARI, Massimo. Comida como cultura. São Paulo: Senac São Paulo. 2008.

ORGANIZAÇÃO DAS NAÇÕES UNIDAS (ONU).Comitê de Direitos Econômicos, Sociais e Culturais. Comentário Geral $\mathrm{n}^{\circ} 12$ - art. 11 do Pacto. 1999. Disponível em: http://fianbrasil.org.br/wpcontent/uploads/2016/12/Comentario-Geral-No-12.pdf. Acesso em: 28 maio 2017.

PESSANHA, Lavínia Davis Rangel. Pobreza, Segurança Alimentar e Políticas Públicas: Contribuição ao Debate Brasileiro. (texto apresentado no Seminário "Sistemas Locais de Segurança Alimentar" realizado no Instituto de Economia da Unicamp em novembro de 2002. 1: Estimativa de Beneficiários de Programas de Combate à Fome, 2001.

RATZEL, Friedrich. Le Sol, la Société et l'État. 1900. Disponível em: < $\mathrm{http}: / /$ classiques.uqac.ca/classiques/ratzel_friedrich/Sol_Societe_Etat/ratzel_le_sol_societe_Etat.pdf $>$. Acesso em: 08 nov. 2017.

ROCHA, Gilmar Rocha; TOSTA, Sandra Pereira. Antropologia e Educação. Col. Temas e educação, 
v.10, Belo Horizonte: Autêntica. 2009.

TEIXEIRA, João Carlos; PAGANINE, Joseana; GUEDES, Sylvio. História: a Rio-92 e as conferências anteriores à Rio+20. Revista Em Discussão, Brasília/DF, ano 3, v.11, p. 12, junho 2012. Disponível em: https://goo.gl/aYPVKC. Acesso em: 07 nov. 2017.

TRICHES, Rosane Márcia. A ressignificação da qualidade dos alimentos na construção de mercados locais: o caso da alimentação escolar. In: $5^{\circ}$ Encontro da Rede de Estudos Rurais, Belém-PA. 2012.

VALENTE, Flávio Luiz Shieck. O direito à alimentação. In: LIMA, Jaime Benvenuto, ZETTERSTRÖM, Lena. (orgs.) Extrema pobreza no Brasil: a situação do direito à alimentação e moradia adequada. São Paulo: Loyola. 2004.

WILKINSON, John. A agricultura familiar ante o novo padrão de competitividade do sistema alimentar na América Latina. Estudos Sociedade e Agricultura, Rio de Janeiro, v.21, p.62-87, 2003.

WRIGHT, Angus. Descendo a montanha e seguindo para o norte: como a degradação do solo e os pesticidas sintéticos orientaram a trajetória da agricultura mexicana ao longo do século XX. Topoi, Rio de Janeiro, v. 13, n. 24, p. 136-161, jan/jun. 2012.

\section{Notas de Rodapé}

3. Também conhecida como Rio-92, Eco-92 ou Cúpula da Terra, a Conferência das Nações Unidas sobre o Meio Ambiente e Desenvolvimento (Cnumad), realizada em junho de 1992 no Rio de Janeiro, marcou a forma como a humanidade encara sua relação com o planeta. Foi naquele momento que a comunidade política internacional admitiu que era preciso conciliar o desenvolvimento socioeconômico com a utilização dos recursos da natureza.

4. Criada em 16 de outubro de 1945, sediada em Roma, a FAO é a maior agência especializada no seio da Organização das Nações Unidas. Fornece a todos os países oportunidade para se reunirem, discutirem ou formularem políticas relacionadas com agricultura e alimentação. Formula normas internacionais, facilita o estabelecimento de convênios e acordos e organiza conferências, reuniões técnicas e consultorias especializadas (FAO, 2016).

5. A partir de fevereiro de 2010, a alimentação foi incluída entre os direitos sociais previstos no artigo $6^{\circ}$ da Constituição Federal. O DHAA realiza-se quando cada homem, mulher e criança, sozinho ou em companhia de outros, tem acesso físico e econômico, ininterruptamente, à alimentação adequada ou aos meios para sua obtenção (Comentário Geral 12, ONU, 1996).

6. Soberania Alimentar é o "direito dos países definirem suas próprias políticas e estratégias de produção, distribuição e consumo de alimentos que garantam a alimentação para toda a população, respeitando as múltiplas características culturais dos povos". (Conceito definido no Foro Mundial de Soberania Alimentaria, realizado em 2001 na cidade de Havana) (CONTI, 2009). 
7. Caíque é bote ou pequena embarcação turca não muito forte, sem ponte, geralmente de fundo chato e proa elevada, movida a remo ou, quando maior, a vela. Usado em transportes ligeiros ou em navegação de cabotagem.

8. Informação obtida através de consulta ao Órgão no dia 20 de dezembro de 2016.

9. A COOPOVEC tem por objetivo organizar os produtores para o plantio de forma escalonada, e comercialização da produção nos programas institucionais, venda em feiras e venda ao consumidor final.

10. Criado em 2003, o Programa de Aquisição de Alimentos (PAA) é uma ação do Governo Federal para colaborar com o enfrentamento da fome e da pobreza no Brasil e, ao mesmo tempo, fortalecer a agricultura familiar. Para isso, o programa utiliza mecanismos de comercialização que favorecem a aquisição direta de produtos de agricultores familiares ou de suas organizações, estimulando os processos de agregação de valor à produção (BRASIL, MDA, 2016).

11. O Programa Nacional de Alimentação Escolar (PNAE), implantado em 1955, contribui para o crescimento, o desenvolvimento, a aprendizagem, o rendimento escolar dos estudantes e a formação de hábitos alimentares saudáveis, por meio da oferta da alimentação escolar e de ações de educação alimentar e nutricional (BRASIL, FNDE, 2016). 